\title{
Newborn resuscitation practices and paucity of resuscitative devices in Nigeria; a call to action
}

\author{
Ikechukwu Richard Okonkwo ${ }^{1}$, Veronica Chinyere Ezeaka ${ }^{2}$, Bello Mustapha $^{3}$, Obum Ezeanosike ${ }^{4}$, \\ Olukemi Tongo ${ }^{5}$, Angela A.Okolo ${ }^{6}$, Eyinade Kudirat Olateju ${ }^{7}$, Raphael Oruamabo ${ }^{8}$, Bede Ibe ${ }^{9}$
}

1. Department of Child Health, University of Benin Teaching Hospital, Benin, City.

2. Department of Paediatrics, Lagos University Teaching Hospital, Lagos.

3. Department of Paediatrics, University of Maiduguri Teaching Hospital, Maiduguri.

4. Department of Paediatrics, Federal Teaching Hospital Abakaliki.

5. Department of Paediatrics, University College Hospital Ibadan.

6. Department of Paediatrics, Federal medical centre, Asaba.

7. Department of Paediatrics, University of Abuja Teaching Hospital, Gwagwalada, Abuja.

8. Department of Paediatrics, Rivers State University of Science and Technology.

9. Department of Paediatrics, University of Nigeria Teaching Hospital, Enugu.

\begin{abstract}
Background: Neonatal resuscitation is a method of preventing morbidities \& mortality from asphyxia. Up to $85 \%$ of facilities in sub-Saharan Africa lack supplies or skilled personnel for neonatal resuscitation. Relative to the place of birth and the skill of the birth attendant, a variety of resuscitative practice are employed to make babies cry instead of helping the baby breathe. Many painful procedures are applied when the baby is unable to cry after birth in the absence of a health care worker trained in bag-mask ventilation.
\end{abstract}

Objectives: To ascertain the resuscitation practices in communities lacking bag-mask-valve devices

Methods: Surveys on the resuscitation practices during NISONM annual community outreach and mENCC trainings for four consecutive years in different geopolitical zones of the country.

Results: Spanking of the baby usually in the upside down position $(>90 \%)$, body massage with hot compress or salicylate containing balms, herbal concoctions, injection hydrocortisone or crystalline penicillin were used.

Conclusion: There is an urgent need to address the issue of training on bag-mask ventilation and provision for frontline healthcare workers in Nigeria as a neonatal mortality reduction strategy.

Keywords: Newborn resuscitation, paucity of resuscitative device, Nigeria.

DOI: https://dx.doi.org/10.4314/ahs.v19i1.30

Cite as: Okonkwo IR, Ezeaka VC, Mustapha B, Ezeanosike O, Tongo O, Okolo AA, et al. Newborn resuscitation practices and paucity of resuscitative devices in Nigeria; a call to action. Afri Health Sci. 2019;19(1). 1563-1565. https:// dx.doi.org/10.4314/abs.v19i1.30

\section{Corresponding author:}

Ikechukwu Richard Okonkwo, Department of Child Health, University of Benin Teaching Hospital, P M B 1111, Benin, City, Edo State, Nigeria.

Email: ikeokonkwo2001@yahoo.com

\section{Introduction}

Neonatal resuscitation is a known method for preventing the morbidities and mortality from birth asphyxia in several low and middle income countries. ${ }^{1-4}$ When capacity for neonatal resuscitation is lacking or deficient, there is a missed opportunity to save neonatal lives. ${ }^{5-8}$ A recent survey showed that $85 \%$ of facilities in sub-Saharan Africa 
lacked supplies or skilled personnel to perform neonatal resuscitation, the Nigerian situation is not different., ${ }^{9,10}$ Babies are expected to cry at birth, it is one of the indicators of wellbeing. Most babies (90\%) would not require any assistance to breathe or cry at birth. About 1 in 10 babies would need some stimulation to breathe at birth, but less than $1 \%$ of babies require extensive help to breathe. ${ }^{11}$ The help required by babies to breathe must be given within the first minute of life to be effective. ${ }^{12}$ The day of birth is the riskiest day of the life10 especially those that fall into the $<1-10 \%$ category that require some help to breathe. ${ }^{12}$ Relative to the place of birth and the skill of the birth attendant, a variety of resuscitative practice may be employed in an attempt to make the baby cry instead of helping the baby breathe.

These resuscitative practices vary from one place to another, and they arise due to lack of the resuscitative device which is the bag-mask-valve. When babies are unable to breathe at birth, this device is used to inflate the lungs of the baby. When this is done timely and properly, many of the babies resume spontaneous respiration.

Due to the age old belief that crying is the indicator of breathing in newborn, many painful procedures are initiated when the baby is not able to cry after birth and in the absence of a healthcare worker trained in bag-mask ventilation. Analysis of data obtained during the last four consecutive community mobilizations and Helping Babies Breathe workshops of NISONM highlighted some of these issues.

As part of the Nigerian Society for Neonatal medicine (NISONM) conference annually, pre-conference activities are held in communities' $15-20 \mathrm{~km}$ from the city centre has been quite revealing. The programme that has been held twice in the South-South, once in the SouthEast and South-West geopolitical zones of Nigeria for the past four years provided similar feedback.

Health care workers from 20 primary health care centres (PHC) in the first instance, 18 PHC and 36 PHC's in the recent meetings lack bag mask-valve device in their delivery rooms. A survey of the resuscitation practice in these facilities showed that spanking of the baby while held upside down by the lower limb $(>90 \%)$ was the mainstay of resuscitation. This was followed by body massaging with hot compresses or salicylate containing balms. These balms could be inserted into orifices like anus and nose to stimulate breathing by causing pain. The use of local herbal preparations were not precluded. Other means of resuscitation also extended to administration of intramuscular injections like hydrocortisone to crystalline penicillin.

It was more revealing that none of the healthcare workers consisting of nurses, community health extension workers (CHEW), and village health workers (VHW) have been trained on bag-mask ventilation neither were they aware of its use in resuscitation. It is imperative from the foregoing that the determinants of neonatal morbidity and mortality which has worse impact on the suburban and rural communities are prevalent. ${ }^{10}$ This may be related to the poor or non-existent neonatal care services. ${ }^{13}$ In the absence of basic resuscitative equipment and healthcare workers lacking resuscitation skills, the desire for reduction in neonatal morbidity and mortality could remain a mirage. There is therefore the urgent need to address the issue of training on bag-mask ventilation and provision of resuscitation devices for the frontline healthcare workers this would herald the beginnings of the Modified Essential Newborn Care (ENCC course) training for these category of workers.

While the passion of these frontline healthcare workers to deliver babies is not in doubt, their resuscitative practices will not change unless they are supported with the bag-mask-valve device, the HBB and the modified ENCC training. ${ }^{2,3}$ This has been the practice of the association in providing each health facility represented in the training with a resuscitation bag containing bag-mask-valve device, suction device (Penguin suction bulb) a mannequin for continued practice, and a stethoscope.

Helping Babies Breathe (HBB) is an evidence-based curriculum for neonatal resuscitation specifically designed for low resource settings and best suited for our locale environment. Its algorithm, or Action Plan, focuses on the basic steps of neonatal resuscitation, including drying/ stimulation, suction, and bag-mask ventilation for the non-breathing infant. HBB relies on simulation to allow resuscitation providers to practice skills, rather than just improve theoretical knowledge. ${ }^{6-8,14}$ As part of the HBB modules, trainees demonstrate clearing the airway and stimulating breathing during The Golden Minute, bag \& mask ventilation and delayed clamping of the cord. This 
involves waiting at least 1 minute, and up to 3 minutes to clamp and tie and cut the cord if the baby is receiving routine care. Delayed cord clamping is beneficial for all infants due to blood transfusion from placenta. Healthy self-breathing neonates in a low-resource setting are more likely to die if cord clamping occurs before or immediately after onset of spontaneous respirations. The risk of death/admission decreases by $20 \%$ for every 10 -second delay in clamping after breathing. Large hospital-based studies in Africa and Asia have demonstrated that implementation of HBB has decreased early neonatal mortality, Asphyxia and stillbirth rates. ${ }^{1-3,6,9,12,14}$ We can indeed change the landscape of neonatal care in Nigeria by providing this training and support to frontline health care workers.

This is a project initiative of NISONM borne out of the desire to make the device widely available and the skill set used in newborn resuscitation.

\section{Conflict of interest}

None.

\section{References}

1. Wall SN, Lee ACC, Carlo W, Goldenberg R, Niermeyer S,Darmstadt G, et al. Reducing intrapartum-related neonatal deaths in low- and middle-income countries-what works? Semin Perinatol 2010; 34: 395- PubMed ;407.

2. Lee AC, Cousens S, Wall SN, Niermeyer S, Darmstadt GL, Carlo WA et al. Neonatal resuscitation and immediate newborn assessment and stimulation for the prevention of neonatal deaths: a systematic review, meta-analysis and Delphi estimation of mortality effect. BMC Public Health. 2011; 11(Suppl 3): S12.

3. Kamath-Rayne BD, Griffin JB, Moran K, Jones B, Downs A, McClure EM, et al. Resuscitation and obstetrical care to reduce intrapartum-related neonatal deaths: a MANDATE study. Matern Child Health J. 2015; 19: 1853 63.

4. Lawn JE, Kinney M, Lee AC, Chopra M, Donnay F, Paul VK et al. Reducing intrapartum-related deaths and disability: can the health system deliver? Int J Gynaecol Obstet. 2009; 107(Suppl 1): S123-S140 S40-2.

5. Berkelhamer SK, Kamath-Rayne BD, Niermeyer S.
Neonatal resuscitation in low-resource settings. Clin Perinatol. 2016; 43(3): 573 PubMed -591.

6. Hill K, Clark P, Narayanan I, Wright LL DV. Improving Quality of Basic Newborn Resuscitation in Low-resource Settings: A Framework For Managers and Skilled Birth Attendants. USAID ASSIST Project: Bethesda, MD, USA, 2014.

7. Ersdal HL, Singhal N. Resuscitation in resource-limited settings. Semin Fetal Neonatal Med. 2013; 18(6): 373 PubMed -378.

8. Niermeyer S, Keenan W, Little G, Singhal N. Helping Babies Breathe: Facilitator Flip Chart: American Academy of Pediatrics, Laerdal Global. Health.http://internationalresources.aap.org/Resource/ShowFile?documentName=hbb_flipchart_english.pdf.

9. Darmstadt G. Global perinatal health: accelerating progress through innovations, interactions, and interconnections. Semin Perinatol. 2010; 34: 367- PubMed ;70.

10. Saving newborn lives in Nigeria: Newborn health in the context of the Integrated Maternal, Newborn and Child Health Strategy. Abuja: Federal Ministry of Health, Save the Children, ACCESS; 2009. www.savethechildren. org/savenewborns.

11. Textbook of Neonatal Resuscitation .American Academy of Pediatrics (AAP) and American Heart Association's (AHA) 2006.

12. Niermeyer S. From the Neonatal Resuscitation Program to Helping Babies Breathe: Global impact of educational programs in neonatal resuscitation. Semin Fetal Neonatal Med. 2015;20(5):300-8.

13. Okonkwo I.R, Okolo A.A, Abhulimhen-Iyoha B. Scope of neonatal care services in major Nigerian Hospitals. Niger J Paed. 2016; 43 (1):8 PubMed - 13.

14. Rule A R L, Mania E, Chruiyot D, Mueri P, Simmons J M, Kamath-Rayne B D. Using quality improvement to decrease birth asphyxia rates after 'Helping Babies Breathe' training in Kenya. Acta Paediatrica. 2017 106, pp. 1666-1673.

15. Ersdal HL, Linde J, Mduma E, Auestad B, Perlman J, Neonatal Outcome Following Cord Clamping After Onset of Spontaneous Respiration. Pediatrics. 2014 Aug;134 (2):265-72. doi: 10.1542/peds.2014-0467. Epub. 2014 Jul 14. 